\title{
O comportamento suicida de idosos institucionalizados: histórias de vida
}

I 1 Maria Cecília de Souza Minayo, ${ }^{2}$ Ana Elisa Bastos Figueiredo,

${ }^{3}$ Raimunda Matilde do Nascimento Mangas I

Resumo: Neste artigo estão resumidas e analisadas 16 histórias de vida de homens e mulheres idosos que residem em nove Instituiçóes de Longa Permanência no Estado do Rio de Janeiro e que tentaram dar cabo à vida ou têm comportamento suicida. $\mathrm{O}$ estudo qualitativo foi precedido por uma pesquisa do perfil de 122 idosos residentes, por meio de um formulário do qual constam: dados socioeconômicos e demográficos: nome, data de nascimento, idade, sexo, estado civil, numero de filhos vivos e mortos, nacionalidade, raça, religião, grau de instrução, profissão/ocupação, renda e tempo em que reside na instituição; e cinco perguntas que direcionaram a seleção das pessoas com ideaçóes e tentativas de suicídio, segundo um modelo criado pelo pesquisador italiano Scocco e seu grupo.

Segundo as histórias narradas pelos oito homens e oito mulheres, observam-se relevantes diferenciaçóes por gênero tanto nos aspectos sociodemográficos como motivacionais para o comportamento suicida. Os principais fatores comuns a homens e mulheres institucionalizados em situação de risco para a morte autoinfligida são: perda de laços afetivos e de pessoas referenciais, abuso de álcool e outras drogas, inadequação à vida institucional, doenças crônicas incapacitantes e dolorosas que repercutem em solidão, desesperança e falta de sentido para a vida.

> Palavras-chave: idoso; suicídio; tentativa de suicídio; ideação suicida; instituição de longa permanência.
1 CLAVES, Escola Nacional

de Saúde Pública, Fundação

Oswaldo Cruz. Rio de Janeiro-RJ

Brasil (maminayo@terra.com.br).

2 Departamento de Estudos de Violência e Saúde, Fundação Oswaldo Cruz. Rio de JaneiroRJ, Brasil (aebfigueiredo@ yahoo.com.br).

${ }^{3}$ Departamento de Estudos de Violência e Saúde, Fundação Oswaldo Cruz. Rio de JaneiroRJ, Brasil (raimangas.mangas1@ gmail.com).
Recebido em: 30/01/2017 Aprovado em: 30/05/2017 


\section{Introdução}

Neste artigo estão resumidas as histórias de vida de 16 pessoas idosas residentes em Instituiçôes de Longa Permanência (ILPI) no Estado do Rio de Janeiro que relatam comportamentos suicidas. A literatura tem utilizado o termo para se referir à conduta da pessoa que busca se ferir ou se matar. Comportamentos suicidas não fatais aparecem sob a forma de ideação suicida, quando há pensamentos que fomentam um anseio de pôr fim à existência e se agrava quando acompanhados de um plano para o autoaniquilamento. A tentativa de suicídio envolve atos que podem chegar ou não à morte autoinfligida (WORLD HEALTH ORGANIZATION, 2002, 2014).

Existem muitas teorias que tentam explicar o porquê as pessoas se matam. A mais antiga e clássica vem de Durkheim (2011), que, ao final do século XIX, analisou este fenômeno e o classificou como um fato social que faz parte da cultura de todas as sociedades. A seu ver, cada uma delas possui uma cota mais ou menos constante de pessoas que optam pelo autoextermínio e suas características são particularmente a de desagregação social e anomia. E, por parte do indivíduo, o egoísmo ou o excesso de altruísmo. Essa regularidade, para Durkheim, torna o suicídio um fenômeno sociológico normal, que pode sempre ser explicado por algumas variáveis próprias de cada cultura. Após Durkheim, e ao longo do século XX, desenvolveu-se uma vasta literatura que seguiu um caminho diametralmente oposto, enfatizando o papel do individuo na escolha da morte autoinfligida e colocando foco nos problemas mentais. Entre esses problemas, são destacados como fatores de risco a depressão, seguida da desordem afetiva bipolar, da esquizofrenia, da anorexia e bulimia nervosa e do abuso de substâncias tóxicas (LYKOURAS et al., 2002; BRADVIC et al., 2009; HEISEL et al., 2011; CANADIAN ASSOCIATION OF MENTAL HEALTH, 2016; MENTAL HEALTH REPORTING, 2016).

Nossa argumentação neste trabalho, fundamentado em estudo de revisóes sistemáticas e de evidências apresentadas pela Organização Mundial da Saúde OMS (WHO, 2014), é que nenhum fator singular é suficiente para explicar por que uma pessoa comete suicídio ou deseja fazê-lo. Seu comportamento é influenciado por um conjunto de elementos que se associam e envolvem razóes pessoais, sociais, psicológicas, culturais, biológicas e ambientais. Assim, embora a própria OMS trate do suicídio na sua divisão de saúde mental, evidenciando o peso desse campo 
científico nas interpretaçôes e intervençôes; considere que 90\% das pessoas que têm morte autoinfligida possuem diagnóstico de distúrbio mental - a maioria, por depressão (WHO, 2014); e exista uma tendência entre os profissionais de saúde de medicalizar o intenso sofrimento que leva alguém a desejar a morte, nossos estudos (CAVALCANTE et al., 2012, 2013, 2015) têm mostrado que é preciso conhecer as circunstâncias em que germinam o comportamento suicida, para compreender o fenômeno e prevenir os múltiplos fatores que o provocam. Nesse sentido, falar de suicídio é falar mais da vida que da morte.

A escolha das ILPI vem do fato de que, no Brasil, 15\% das mortes autoinfligidas dessa população ocorrerem aí ou em hospitais (PINTO et al., 2012). Na literatura nacional não existem estudos sobre a incidência de tentativas e ideaçóes entre idosos institucionalizados, sendo este o primeiro trabalho sobre o assunto. Igualmente, na literatura internacional são poucas as referências (ANÍA et al., 2003; KU et al., 2009; MALFENT et al., 2010; SCOCCO et al., 2006, 2009).

No Brasil, as residências para idosos apresentam uma diversidade imensa em sua organização e forma de funcionamento, o que está bastante detalhado nos estudos de Camarano et al. (2010) e de Figueiredo et al. Elas são reguladas pela Agência Nacional de Vigilância Sanitária (ANVISA, 2005), que hoje responde por sua adequaçáo aos preceitos da saúde e do Estatuto do Idoso. Mesmo quando seguem todas as normas para proteção dessa população, uma ILPI sempre será um ambiente artificial e regulado quando comparado com a casa onde a pessoa passou sua vida.

O trabalho aqui apresentado se fundamenta em autores que analisam especificamente tentativas e ideaçôes suicidas nessas residências. A partir da compreensão das falas dos idosos que vivem em tais instituiçôes, pretende-se demonstrar que o final da existência é o ápice de um curso de vida de sofrimento - muitas vezes iniciadas na infância -, em que circunstâncias e escolhas levam alguns ao intenso desejo de antecipar seu fim (CAVALCANTE et al., 2015).

\section{Método}

Foram ouvidos oito homens e oito mulheres internados em nove ILPI do Estado do Rio de Janeiro que apresentavam sinais de ideaçóes e tentativas de dar cabo à vida (duas da capital, três da Baixada Fluminense e quatro do Interior do Estado), utilizando-se critérios aplicados por Camarano et al. (2010) para classificar essas 
residências no país: estrato social, atendimento específico a pobres e específico à classe média; instituiçôes públicas, filantrópicas e privadas; e instituiçôes para homens e mulheres separadamente, e mistas.

No acesso a essas instituições, a condição preliminar foi a aceitação institucional para que a pesquisa fosse realizada em suas dependências. No caso do aceite, o estudo ocorreu em duas etapas. A primeira visou ao conhecimento do perfil dos idosos residentes nas unidades selecionadas, com ou sem história de comportamento suicida. A segunda aprofundou a interlocução com aqueles que apresentavam sintomas de comportamento autoagressivo.

Os 122 idosos ouvidos na primeira etapa responderam a um formulário do qual constam: dados socioeconômicos e demográficos: nome, data de nascimento, idade, sexo, estado civil, número de filhos vivos e mortos, nacionalidade, raça, religião, grau de instrução, profissão/ocupação, renda e tempo em que reside na instituição; e cinco perguntas que direcionaram a seleção das pessoas com ideaçôes e tentativas de suicídio. A reposta positiva a três dessas cinco questóes - segundo o "Instrumento de Avaliação de Residente" - RAI (SCOCCO, 2006) - foi considerada indicativa de risco. As três primeiras, sugestivas de ideação; as duas últimas, de tentativas. São as seguintes as cinco questôes: Após os 60 anos, já teve a sensação de que sua vida não valia a pena? Alguma vez, depois dos 60 anos, já quis dormir e nunca mais acordar? Alguma vez, após os 60 anos, você pensou em tirar a própria vida, mesmo que nunca fosse fazer isso? Alguma vez, depois dos 60 anos, considerou seriamente tirar a própria vida, ou fez planos de como fazer isso? Alguma vez, após 60 anos, tentou tirar sua própria vida? Como já dito, do total, 16 idosos apresentaram ideações e tentativas de suicídio e é sobre eles este texto.

Considerou-se que a abordagem qualitativa denominada "historia de vida" seria a mais adequada para guiar a conversa com os idosos, pois nossa hipótese era que o comportamento suicida fala mais da existência como um todo do que de um ou mais atos que possam ser analisados topicamente. Quando ele ocorre na velhice, manifesta-se na forma de um sofrimento que integra a trajetória existencial, cujo momento disparador pode ter começado na infância, na vida adulta, ou mesmo na última etapa do ciclo de vida. Ou, ainda, pode ser a culminância dos vários fatos que atravessaram, de forma negativa, a biografia pessoal.

A importância de se trabalhar com história de vida vem do fato de o pesquisador ser contemporâneo de seu objeto-sujeito (BERTAUX, 1981). Ao 
seguir a narrativa de seu interlocutor, o pesquisador supera a descontinuidade

fundamental que costuma existir entre seu aparato intelectual, afetivo e psíquico e o dos homens e mulheres cujas histórias ele escreve. Mas a história contada não é uma sobrevivência do passado, é uma imagem construída pelos materiais que estão, agora, à disposição, no conjunto de representaçôes que povoam a consciência atual da pessoa, pois a percepção dos acontecimentos se altera com a poeira do tempo e em contato com outras vivências que compóem o mosaico da vida tal qual se mostra no presente (BOSI, 1987; HALBWACHS, 1990).

Com cada uma das 16 pessoas em risco para o suicídio foi realizada uma conversa em profundidade sobre sua situação. A condução do trabalho exigiu intensificar a escuta do que Goy (1980) assinala como um arquivo pessoal que entrelaça o verdadeiro, o vivido, o adquirido e o imaginado. As histórias foram contextualizadas segundo as condiçôes sociodemográficas, a vida social e de trabalho; os relacionamentos com familiares, vizinhos e amigos; a vivência institucional e as circunstâncias em que ocorreu o comportamento suicida. Os nomes utilizados para identificação das pessoas são fictícios.

A análise das informaçóes dá ênfase aos aspectos considerados relevantes pelas pessoas idosas, buscando a compreensão de suas falas e, ao mesmo tempo, contextualizando-as no tempo e no espaço segundo sexo, uma vez que foram ouvidos oito mulheres e oito homens.

A pesquisa que deu origem ao artigo foi aprovada pelo Comitê de Ética em Pesquisa (CEP) da Escola Nacional de Saúde Pública, sob o número 160.564, em 2/12/2012. Além de cumprir os procedimentos previstos pela Resolução no $466 / 12$, todas as pessoas entrevistadas que tiveram necessidade de algum tipo de acompanhamento foram encaminhadas às instâncias institucionais competentes para os cuidados adequados.

\section{Resultados}

Os idosos que tentaram suicídio ou revelaram ideaçôes suicidas possuem idades que variam entre 60 e 88 anos. A faixa etária entre 60 e 69 anos é onde se concentra a maioria dos que têm comportamento de risco, vindo a seguir a de 80 anos e mais e, em terceiro lugar, a de 70 a 79 . Das oito idosas, quatro tentaram a morte autoinfligida e todas planejaram ou têm severas ideaçôes. Dos homens, todos tiveram ou têm severas ideaçôes suicidas e três já tentaram se matar. A 
maior parte dos casos de tentativa ocorreu antes de essas pessoas serem internadas em ILPI, mas a experiência persistente de ideação continua como um estado latente de vulnerabilidade.

Existem algumas questóes comuns entre os idosos e as idosas. Com exceção de um homem e uma mulher, todos são pobres. Todos passam hoje por abandono e negligência familiar, vive ou do piso da aposentadoria ou do benefício de prestação continuada, que é equivalente a apenas um salário mínimo.

Contexto e circunstâncias das ideaçôes e tentativas de suicídio entre as mulheres - Existem mais diferenças que semelhanças quando se comparam homens e mulheres. A idade das senhoras institucionalizadas (média 76 anos) é mais elevada que a dos homens (68 anos). É importante observar o baixo status social dessas senhoras cujo nascimento ocorreu entre a década de 1930 e 1950. Todas são pessoas com pouca instrução, evidenciando uma época em que a educação formal era privilégio de poucos, mas, principalmente, de poucas mulheres. Das oito, quatro são analfabetas, duas estudaram até o segundo ano primário e duas completaram o nível fundamental básico. A pouca formação escolar é indiscriminada pela condição social. O universo doméstico foi o mundo de todas. Quatro trabalharam como empregadas domésticas, três das quais não se casaram e não tiveram filhos, porque dedicaram toda a vida "à casa dos outros", ou "aos filhos dos outros", como referem. Uma delas é mãe solteira de um filho que é seu provedor. Nenhuma recebe visitas ou cuidados por parte dos antigos patróes, pois eles não mantiveram vínculos com elas quando envelheceram. Ao contrário, elas têm um forte ressentimento por terem sido abandonadas. As outras quatro, cuja prole se distribui entre seis e três filhos, formaram família. Hoje também elas se sentem relegadas pelos filhos. Três são viúvas, que os filhos preferiram não acolher e cuidar delas em suas casas.

De todas as oito mulheres, apenas uma optou pelo lugar onde está. Dona Linda, por exemplo, tem 79 anos e teve sete filhos, mas conta que foi obrigada a doá-los todos, por causa da extrema pobreza da família. Hoje não tem ninguém que a cuide. Comenta que levou uma vida de privação e sofrimento e agora: "quero me atirar em cima de alguma coisa lá em baixo. Não sei o porquê, mas me matar é uma ideia constante." A falta do universo familiar e afetivo é o que mais incomoda essas mulheres, que se sentem esquecidas por aqueles a quem dedicaram suas vidas e desconfortáveis por estarem privadas de "suas coisinhas" e de seu espaço 
doméstico. Os pensamentos ou tentativas de morte sobrevêm numa sensação de solidão inenarrável e de uma desesperança profunda, pois elas têm a consciência de que a residência onde vivem hoje é sua última parada antes da morte.

"Sempre fui rejeitada e explorada: minha vida não tem sentido", comenta Dona Maria. E se pergunta: O que estou fazendo aqui?”, confidenciando que suas ideias de se matar são persistentes e que já tentou suicídio três vezes com chumbinho, com formicida e jogando-se na frente de um caminhão. No mesmo tom de desesperança se expressa Dona Ana, que tem 80 anos e se considera "sozinha no mundo". Marcada por ser órfá de mãe, abandonada e maltratada pelo pai e depois explorada por patrôes que a tomaram a seu serviço doméstico já aos oito anos de idade, refere: "nunca aprendi mais nada na vida, só o trabalho na casa dos outros." Explica que tentou dar cabo à vida por três vezes: "foi com veneno de formiga." "Todo dia peço a Deus para me tirar deste mundo, pois estou triste e sofro."

Dona Dina tem 84 anos e também trabalhou em casa de família desde a adolescência. Relegada na velhice, encontrou espaço na ILPI, onde reside, sem receber visitas e em total solidão: "já não presto para mais nada, vou acabar com minha vida." Levou um tombo ao ser agredida por outra interna dentro da própria instituição, o que lhe trouxe uma fratura de fêmur e dependência numa cadeira de rodas: "aqui eu não faço nada e só tenho esperança de sair morta. O que eu sinto é tristeza, solidão e depressão." Dina tentou suicídio três vezes: "peguei álcool e taquei fogo em mim." Acrescenta que nas outras ocasióes, bateu com o martelo na cabeça e ensaiou se jogar de um ônibus andando. Comenta que os pensamentos suicidas lhe aparecem principalmente quando se deita à noite $\mathrm{e}$ fica "remoendo".

Dona Livia tem 88 anos, é mãe solteira e independente física e mentalmente. Detesta estar numa ILPI e afirma: "só penso em me matar, porque eu quero sair daqui e não posso." Lívia conta que sempre pediu a Deus que a livrasse de morar numa residência para idosos: "Deus não me livrou!" Sente muita falta de sua casa e de seus pertences. E comenta que não conhece nem tem intenção de conhecer ninguém na ILPI, apesar de estar aí há mais de um ano. Um dos seus descontentamentos é não ter permissão para sair a não ser acompanhada. Encontra-se em total solidão, "tem noite que eu choro a noite inteira de tristeza" e "penso que eu podia me matar". Completa: "tenho vários motivos. Eu quero sair 
daqui e não posso, meu filho não vai me levar. Não tem jeito." Confidencia que arranjou um lenço para se enforcar. Mostra o que traz no pescoço e diz: "seria um lenço assim. O dia em que me der a louca e eu não suportar mais...” Embora reze para afastar os pensamentos suicidas, comenta que eles não vão embora e ocorrem principalmente à noite, quando fica "remoendo as ideias".

Dona Ema com 74 anos, Dona Iolete com 62 e Dona Irene com 83 são viúvas. Dona Ema fala de um casamento conflituoso no qual sofria maus-tratos do marido alcoólatra e menciona a continuidade de uma família com laços conturbados e frouxos. Os filhos a abandonaram na ILPI: "me colocaram aqui e nem me visitam." "Tenho que acabar com minha vida e com meu sofrimento." "Pois só vive no asilo quem não tem mais ninguém." Tentou suicídio em casa: "eu estava num desespero muito grande, desprezada e sozinha: comprei soda cáustica e formicida. Eu ia beber e aí chegou uma vizinha e não me deixou."

Dona Irene assim expressa seu desejo: "meu marido morreu. Meu lugar é perto dele no cemitério." Sua família de pequenos empresários possui uma padaria e ela tinha uma boa casa, "meu quarto, minhas coisinhas". Mas os filhos tomaram tudo, colocaram-na na instituição e não a visitam. Interpreta a ausência dos familiares como falta de carinho e atenção. Reclama que também os antigos amigos se afastaram. Ao falar sobre suas persistentes ideaçóes suicidas, Irene revela com tristeza na voz: "peço a Deus que tire de mim esses pensamentos. Mas se for para eu ficar toda a vida numa cadeira de roda ou em cima de uma cama, que ele me tire. Papai do céu já me deixou viver 80 anos. Já estou com 83, chega!"

Dona Iolete conta que nem conheceu os pais, sempre viveu na casa dos patróes, de onde saiu só depois de casada. Teve filhos, mas suas relaçôes com eles sempre foram muito frouxas, pouco afetuosas, e depois que o marido morreu, a solidão é total. Resume assim suas ideações: "tenho vontade de ir embora de vez." A viuvez e o afastamento dos três filhos vivos tiraram-lhe a vontade de viver. Tentou suicídio tomando água sanitária: "Me deu aquela vontade de me matar e puxei o frasco da mão da enfermeira. Ela me segurou e não deixou." Confidencia que os desejos de morte vêm principalmente na insônia da noite.

Contexto e circunstâncias das ideaçóes e tentativas de suicídio entre os homens - Os oito homens institucionalizados têm perfis e histórias bastante diferentes das mulheres, a começar pela idade, pois se internaram mais cedo: apenas três deles têm mais de 70 anos, sendo o mais velho com apenas 74 . Do ponto de 
vista da formação escolar, nenhum é analfabeto, diferentemente das mulheres.

Dois têm formação técnica, três completaram o antigo curso ginasial, dois concluíram o curso primário e um chegou até ao terceiro ano. Enquanto as mulheres todas mencionaram atividades domésticas, os homens descreveram profissōes ou atividades exercidas no passado: administrador, comerciário, radialista, motorista, técnico em eletrônica, operário metalúrgico, de construção civil. No entanto, sua história familiar é bastante frustrante: dos oito, cinco são separados de suas esposas e três são solteiros. Enquanto todas as mulheres cumpriram seu destino doméstico até a institucionalização - seja em casa dos patróes ou em suas residências -, nenhum dos homens estava com a família antes da institucionalização; cinco têm uma trajetória de desfiliação, que vai da saída de sua casa, expulsos pela mulher e pelos filhos por causa de abuso de álcool ou outras drogas; seis viveram pelas ruas e passaram por vários abrigos até chegarem à ILPI, onde residem hoje.

Num ponto, idosos e idosas se assemelham: na queixa pela solidão que sentem, particularmente, pelo abandono por parte dos familiares. Porém, diferentemente delas, que se colocam numa posição de vítima, cinco deles reconhecem que seu destino de abandono foi traçado por eles próprios quando se entregaram à bebida e outras drogas, tornando-se irresponsáveis pelo seu lar. Pelo menos três têm um sentimento de culpa que os atordoa. Mas os homens reagem melhor ao regime de internato - embora nenhum deles goste "desta vida". Alguns costumam sair da instituição para passear, encontrar colegas e têm maior domínio sobre o pouco dinheiro que recebem, cuja parte maior se destina a contribuir com os gastos da própria internaçáo. Dois dos entrevistados se encontram em processos de superação dos desejos de morte, um deles ajudado por uma psicóloga e outro, por um apoio religioso. Ambos pensam em retomar a vida e ter uma companheira fora da instituição, algo impensável dentro da perspectiva das mulheres.

Dos três senhores levados para a ILPI por terem sofrido um acidente vascular cerebral (AVC), o mais revoltado é o senhor Carlos (73 anos), que tinha uma vida ativa e hoje está numa cama, solitário, triste e com dificuldade para andar e falar. Desabafa: "minha vida perdeu sentido." Carlos tem severas ideaçóes suicidas particularmente à noite quando, na sua solidão, alimenta ressentimentos por estar numa ILPI, por não ter acesso a seu dinheiro e pelo abandono da família. Conta que antes da internaçáo morava sozinho, pois não se dava bem com a 
família e aqui não se relaciona com ninguém. Detesta estar na ILPI: "é péssimo, sem liberdade, sem família e sem amigos."

Também vítima de um AVC, o senhor José repete a mesma expressão de Carlos: “minha vida não tem mais sentido. Estou sozinho.” Tentou suicídio duas vezes. Na primeira, ensaiou se atirar da janela do quarto e foi impedido pelo grito do neto, que o estava visitando. $\mathrm{Na}$ segunda, pegou um cordão e deu um nó no pescoço e o funcionário que cuida dele o impediu. Atribui tal comportamento à solidão, à ausência da família e às dificuldades pessoais decorrentes do AVC: para falar, andar, realizar as atividades diárias e pelas dores. Com apenas 68 anos, esse senhor também é separado da esposa e possui dois filhos que não se importam com ele. O AVC o colheu em pleno desempenho profissional. Sua fala monossilábica é carregada de tristeza e solidão. Com voz embargada, diz sentir-se "péssimo" e quer morrer.

Como os outros dois, o senhor Jorge (68 anos) foi vítima de um AVC e também é um inadaptado à condição atual: "sinto-me preso neste lugar e nesta vida." Tentou se matar e tem persistentes ideias suicidas. Perguntado pelos motivos, menciona a decepçáo com a pessoa com quem conviveu durante anos e conta como se mataria: "me jogaria embaixo do ônibus." Mas insiste que já fez isso: "fui para lá e joguei meu corpo debaixo. Juntou um monte de gente e me perguntou o que estava acontecendo. Se o motorista sai com o carro, essa hora eu não estaria aqui." Está no abrigo há um ano e dois meses e é aposentado. É a primeira vez que se interna, pois com o AVC náo estava em condiçôes de se locomover sozinho. Jorge, como os outros, reclama da ausência da família, dos amigos e da mulher com quem compartilhou afetos e que o abandonou quando ele adoeceu. Dos três é o que está se esforçando mais para superar as sequelas do AVC: "eu me esforço. Quanto mais eu andar melhor. Eu entrei aqui com andador e hoje não preciso de ninguém para me ajudar."

No grupo dos homens há dois solteiros. Um deles, o senhor Miro (68 anos), resume assim seu desejo de dar cabo à vida: "quero morrer e ir para perto de minha mãe.” Miro tem severas ideaçôes suicidas, motivadas pela solidão e pelo desamparo que sentiu quando a mãe, com quem mantinha uma relação infantilizada e simbiótica, faleceu. Embora tenha o curso ginasial completo e tenha trabalhado na construção civil, como metalúrgico e como comerciário, seus empregos foram sempre descontínuos, pois vivia a expensas da mãe e bebia 
muito. Hoje recebe o benefício de prestação continuada e considera uma felicidade ter conseguido um lugar na ILPI, onde está há seis anos. Atualmente, está num processo de valorizaçáo pessoal, deixou a bebida e faz trabalhos voluntários dentro da própria instituição.

Assim como Miro, o senhor Severo (73 anos) sente-se frustrado na vida: "fui rejeitado e maltratado, e tenho vontade de ir embora de vez." Com persistentes pensamentos suicidas, esse senhor enfatiza a rejeição do pai na infância e a falta de apoio do meio artístico e da sociedade para realizar seu sonho de poeta e compositor. Explica como planeja dar cabo à vida: "vou parar de comer, vou fazer uma greve de fome.” Apesar de ter se tornado evangélico e assim sentir-se mais protegido contra as ideias de morte, insiste: "em alguns momentos sinto-me muito só e tenho vontade de ir embora dessa vida." Toda a sua trajetória é marcada pela frustração de não ter conseguido êxito como artista e poeta. Expulso de casa, buscou meios de se realizar, primeiro em São Paulo e depois, no Rio de Janeiro, sempre sem sucesso. Morou na rua, passou a beber e o único trabalho formal que já teve foi o de ajudante de pedreiro. Hoje vive com o benefício de prestação continuada e reside na ILPI há nove anos. Mesmo dentro da instituição continua a se queixar da falta de oportunidade, não tem amigos e nenhum tipo de relacionamento com a família.

Os outros quatro senhores também têm a trajetória marcada pela bebida. Quanto ao comportamento suicida, o senhor Antônio (67 anos) chega a ser peremptório: "Que se dane se eu morrer." Tentou se matar duas vezes por overdose de medicamento. Comenta que a vontade de dar cabo à vida surge de repente. "Um aborrecimento e já fica passando pela cabeça." Embora tenha exercido a profissão de comerciário, a bebida o abateu: deixou o emprego, separou-se da mulher e dos filhos, viveu na rua e acabou internado num hospital psiquiátrico, do qual conta que "tomava remédios muito fortes e ficava igual aos outros, andando para lá e para cá”. Antonio ressalta que se sentiu muito só nos momentos de grande sofrimento: "nunca apareceu ninguém." Sua única âncora foi uma psicóloga do Instituto Pinel, que o ajudou: chegava lá bêbado e ela me acolhia: 'pode entrar, você veio aqui porque está precisando de ajuda.' Na ILPI, seus relacionamentos são apenas formais: "não gosto do ambiente." Antônio é bastante autônomo, parou de beber, mas a ausência de perspectivas e a perda dos laços familiares o torturam persistentemente. 
O senhor Aldemar tem trajetória semelhante e assim resume seu desejo de morte: "Claro que minha vida acabou, não tem sentido." Alimenta persistentes pensamentos suicidas, motivados, a seu ver, por sentimentos de culpa, solidão e revolta. Comenta que sua situação melhorou depois de se filiar à religião católica, mas continua a sentir imensa insatisfação com a vida, com a qual pensa em acabar: "Uma fórmula eu já tenho: tomar soda cáustica que é vapt-vupt. Isso é de fórum íntimo." Apesar de dizer que Deus lhe dá suporte e contenção em relação a tais ideias, o sentimento de desesperança persiste: "Não existe mais domingo nem natal." Aldemar estudou até a $3^{\text {a }}$ série ginasial. Foi motorista de táxi e de ônibus. Mas hoje o ampara apenas o benefício de prestação continuada. Está institucionalizado há três anos. $\mathrm{O}$ abuso de bebidas alcoólicas levou-o a deixar sua cidade, sua família e seu trabalho. A mulher o expulsou de casa: "Se você tiver vergonha na cara, não volte mais." Foi viver na rua e não teve mais contato com os parentes. Sua vinda para a atual ILPI foi voluntária, e sua vaga, intermediada por uma assistente social. Apesar de ser grato por residir num lugar seguro, seu relacionamento com os demais internos do abrigo é distante e frio. Com os profissionais também cultiva distanciamento. Considera que a ILPI é um lugar para pessoas que fizeram por merecer estar aí: "pobres sem condição financeira e pessoas que têm que pagar pelo que fizeram na vida." Sua fala é marcada pela tristeza e pela falta que sente da família.

O caso do senhor Pedro, um profissional da área de informática e músico, impressiona: "A cocaína me destrambelhou: eu perdi meus limites!" Teve e continua a ter persistentes ideias suicidas. Elas "entram no pensamento como um tipo de sugestáo". Causam-lhe tristeza, e quando está nessa situação, usa uma alternativa: "busco ouvir os problemas dos outros internos." Comenta que, apesar de estar num processo de superação, tentaria o suicídio das formas mais violentas possíveis: "Jogar-me de um lugar bem alto ou de um trem em alta velocidade." Em seguida, ressalva que Deus não lhe permita realizar o que pensa, pois "seria um ato de muita responsabilidade", e chora. Sua vida se descarrilou com a entrada no mundo das drogas: "o que eu tinha se acabou. Caí na rua. Ninguém me dava mais trabalho. Perdi minha esposa e meus filhos.” Pedro está na ILPI há pouco mais de seis meses, recebe o benefício de prestação continuada e tem buscado se recuperar com o apoio de um Centro Espírita, onde participa de oficinas de leitura, aprende coisas novas e tem apoio psiquiátrico e psicológico. 
Ele e o Sr. Miro são os únicos que estão numa trajetória de superação. Pedro tem

planos para o futuro, pensa em se casar de novo. Hoje na instituição faz musica, ajuda no cuidado com os outros internos e monta e conserta os computadores.

\section{Reflexóes sobre as histórias de vida}

Serão discutidos alguns tópicos cuja relevância se encontra nas próprias narrativas: a perspectiva de gênero; a relação entre comportamento suicida e trajetória de vida; a relação entre ideaçóes e tentativas e institucionalização; os fatores de risco e de proteção.

O primeiro ponto a ser observado é que das 122 pessoas vivendo em ILPI entrevistadas na pesquisa, 16 apresentaram comportamento suicida, o que representa $13,11 \%$ do total com severas ideaçóes e 5,75\% que já tentaram dar cabo à vida. A maioria dos idosos, inclusive em condiçôes sociais e de saúde semelhantes ao grupo dos 16, não demonstram desejos de morte autoinfligida, mostrando-se mais adaptados e resilientes à vida institucionalizada. No entanto, é impossível avaliar se esse percentual é muito ou pouco elevado para a situação brasileira, pois não há estudo anterior sobre o tema. Internacionalmente existem alguns dados que não permitem comparação pelas diferentes metodologias usadas. A título de exemplo, Malfent et al. (2010), numa pesquisa com 129 idosos vivendo em residências geriátricas de Viena, descobriram que 56 deles $(43,41 \%)$ apresentavam desejos persistentes de morte. Anía et al. (2003), numa amostra de 930 prontuários de idosos falecidos no mesmo tipo de residências na Espanha, encontraram 2\% que haviam cometido suicídio. Em um estudo de Scocco et al. (2009), com 288 idosos internados na cidade de Veneza, 37 (21,5\%) disseram que a vida não valia mais a pena; $33(19,2 \%)$ já tinham desejado morrer; sete $(4,1 \%)$ já haviam pensado seriamente e quatro $(2,3 \%)$ haviam planejado se matar. Ouvindo o relato de todos os idosos aqui estudados, três questôes surgem como mais relevantes para homens e mulheres: ausência de laços afetivos, solidão, desesperança e sentimento de perda do lugar no mundo.

Perspectiva de gênero - Na descrição da situação de homens e mulheres existem mais diferenças que semelhanças entre ambos, embora a literatura internacional sobre comportamento suicida em ILPI não discrimina as situaçôes por gênero, ponto que se mostrou relevante nesta pesquisa. Além de terem mais idade e menos escolaridade, as mulheres acabam institucionalizadas porque já não conseguem 
mais trabalhar nas atividades caseiras. As oito, ou foram empregadas domésticas que levaram a vida servindo os patrôes e não têm o seu amparo ao final da vida ou são viúvas a quem os filhos preferem não acolher em suas casas, como mostram os estudos de Beautrais et al. (2006); Meneghel et al. (2012, 2015); Minayo et al. (2013) Nenhuma optou pelo lugar onde está: elas se sentem renegadas por aqueles a quem ofereceram afeto na vida e desconfortáveis por estarem privadas de "suas coisinhas" de seu espaço doméstico e do afeto de familiares e amigos. Seus pensamentos ou tentativas de morte correspondem a uma solidão inenarrável e a uma desesperança profunda por saberem que não reaverão o que tinham. Apesar de nas ILPI haver profissionais e cuidadores à disposição, quase todas reclamam da falta de ajuda, da ausência de intimidade e da perda da privacidade, evidenciando problemas de adaptação por terem que seguir uma rotina totalmente diferente da que tinham em casa e de conviver com pessoas totalmente desconhecidas. Apenas uma mencionou ter depressão. $\mathrm{O}$ que todas vivenciam é um estado depressivo provocado pelas circunstâncias passadas e atuais de sua dura vida, onde dominam solidão, tristeza e desesperança, como assinalado nos estudos de Cavalcante et al. (2012, 2013, 2015) e Klonsky et al. (2012).

No caso dos homens, o comportamento suicida gira em torno de dois problemas: (1) cinco deles têm histórias marcadas por alcoolismo e um por adição a cocaína, o que os afastou definitivamente das famílias, do trabalho e os levaram a viver na rua. A literatura internacional e nacional menciona a relevância desse ponto (CLEARY, 2012; MINAYO et al., 2012); (2) três sofreram AVC e foram deixados nas instituiçóes por familiares, que não se dispuseram a cuidá-los. Os estudos apontam o peso das enfermidades degenerativas e dolorosas, na associação com o comportamento suicida (SZANTO et al., 2002; CAVALCANTE et al., 2016; SILVA et al., 2016; MINAYO et al., 2016). Observa-se também que os homens são menos queixosos, mais independentes e mais colaborativos dentro da instituição que as mulheres, exceto os que estão dependentes por causa do estado de saúde. Todos, porém, são muito críticos das ILPI onde estão abrigados. A maioria é revoltada com a família, com a ausência de afeto por parte dos filhos e de outros parentes. Seu comportamento suicida corresponde à consciência de que estão num caminho sem volta (com exceção de apenas um senhor), que sua vida não tem mais sentido e que o suicídio significa o fim de seus sofrimentos. Três pontos os diferenciam mais das mulheres: um é a religião, que para alguns 
têm servido como fator de contenção (ANÍA et al., 2003; CAVALCANTE et al., 2016); outro é sua maior liberdade no uso do pouco dinheiro que recebem. E, por fim, eles tendem a assumir as responsabilidades pela situação em que se encontram (particularmente os que se entregaram à bebida), enquanto as mulheres se colocam preferencialmente no lugar de vítima da vida.

Comportamento suicida e trajetória de vida - Os estratos de histórias de vida mostram que o comportamento suicida de pessoas idosas institucionalizadas não é um ato isolado no tempo: faz parte de um longo percurso existencial que, ao final, culmina com dor, tristeza, desesperança e escolha da morte como solução para um sofrimento insuportável. Por isso, concluímos que as ideaçôes e tentativas falam muito mais da vida que da morte, ressaltando a face cruel de uma sociedade individualista que, representada pela família ausente, mostra o eloquente silêncio de um país que ainda não despertou para sua responsabilidade social diante do irreversível envelhecimento populacional.

Comportamento suicida e institucionalização - Não são muitos os estudos sobre comportamento suicida de idosos institucionalizados. Os poucos que existem mostram, de um lado, o quão difícil para eles é a vida nas ILPI; de outro, que, para alguns, a internação foi a única solução viável ante o abandono social. Um ponto importante deste estudo é o que revela apenas uma das tentativas de suicídio no contexto institucional. Todos os outros episódios aconteceram em momentos da vida em que os sofrimentos foram considerados insuportáveis. Essa constatação reafirma o que tem sido observado por autores como Szanto et al. (2002), Malfent et al. (2010), Scocco et al. (2009), Figueiredo et al. (2015, 2016), que ressaltam o papel protetor das residências geriátricas em relação à morte autoinfligida. Embora de forma mais impessoal que nas famílias, existe nelas uma vigilância permanente, garantia de cuidados básicos e menos acessibilidade aos meios para consumar o ato fatal (MANGAS et al., 2016). No entanto todas as referidas 16 pessoas continuam a ter persistentes ideaçóes e desejos de morte. Se esse comportamento as levará a atentar contra a própria vida não foi analisado nesta pesquisa, mas essa transição de um momento a outro tem sido assunto das investigações de May et al. (2012) e Klonsky et al. (2012). É importante observar também que, independentemente de sua satisfação ou não com a instituição e de nelas haver profissionais e cuidadores que, em geral, atuam de forma profissional, todas as pessoas ouvidas reclamam da falta de liberdade, de privacidade, de afeto, de apoio e de acompanhamento personalizado (MINAYO et al., 2016). 
Fatores de risco - Dos vários fatores de risco para o suicídio de idosos, descritos pela literatura (TURVEY et al., 2002; YIP et al., 2003; AWATA et al., 2007; WIKTORSSON et al., 2011), os que se mostraram mais relevantes nos casos estudados para ambos os sexos são as condiçôes de vida precária, a violência na infância, os laços familiares frouxos ou conflituosos, o abandono físico e afetivo, a morte de pessoas referenciais, os problemas crônicos e incapacitantes de saúde e as dificuldades de adaptação à vida institucional. Para as mulheres, o maior peso é a inadequaçáo ao espaço institucional, a perda do marido, dos filhos, de seu lugar no lar, de seus pertences e o sentimento de solidão. Para os homens, as doenças incapacitantes e abuso de álcool e drogas são os principiais elementos disparadores. Essas constataçóes são confirmadas pelos estudos de Anía et al. (2003), Ku et al. (2009), Malfent et al. (2010) e Scocco et al. (2006, 2009).

Fatores de proteção - Qualquer estudo sobre o fenômeno do suicídio só tem sentido quando se tem a convicção de que é possível preveni-lo, como preconiza a Organização Mundial da Saúde (2015). Do ponto de vista institucional, vários autores ressaltam que, no caso da pessoa idosa, é preciso cuidar de seu bem-estar físico, de seu estado emocional e, sobretudo, de suas relações e da participação em atividades em que ela se sinta útil e valorizada, o que é particularmente importante numa ILPI. Para isso, ela necessita de uma atenção personalizada. Aqui reside um dos maiores problemas das ILPI estudadas, pois, embora tenhamos observado nelas um comprometimento com os residentes, tanto por parte dos profissionais como dos gestores, numa pesquisa realizada com eles, acompanhando o presente estudo, todos foram unânimes em afirmar que se sentem despreparados para apoiar as pessoas idosas em risco de suicídio (FIGUEIREDO et al., 2016; SILVA et al., 2016). No entanto, foi possível observar um cuidado personalizado pelo menos em relação a dois dos homens entrevistados, que estão conseguindo se reencontrar e se valorizar, colaborando, inclusive, com a própria instituição no cuidado com outros residentes.

Um ponto relevante encontrado nesse grupo é sua dificuldade de entrosamento, de relacionamento e de participação no cotidiano e nos eventos institucionais, relevando uma tendência a se isolar e a exacerbar críticas tanto em relação aos colegas, como aos cuidadores. Um dos fatores de proteção contra o comportamento suicida mencionado por vários autores é a religião (ANÍA et al., 2003; BOTEGA et al., 2006; FLECK et al., 2003; CAVALCANTE, 2016). No entanto, neste estudo, este é um ponto bastante controverso. Das oito mulheres pesquisadas, 
das quais sete disseram ter religião, suas crenças não estão funcionando como um dispositivo preventivo, pois elas invocam a Deus, não para dar-lhes proteção contra o risco de cometer suicídio, mas como uma força superior que as tire o mais prontamente possível deste mundo. Já no caso dos homens, pelo menos dois têm encontrado na fé e na comunidade religiosa apoio e a força para vencer o alcoolismo, as drogas e superar os pensamentos de morte.

A questão da familia, do estado e da sociedade - Nos relatos aqui sumarizados, a família ou a falta que ela faz consumiu bastante tempo de todas as narrativas, levando a pensar que a perda dos laços afetivos e a solidão pela ausência ou perda dos seres mais queridos são os principais disparadores do extremo sofrimento que levou as pessoas aqui citadas a tentar se matar ou a desejar fazê-lo. Num longo estudo sobre suicídio consumado e comportamento suicídio de idosos, esse ponto foi exaustivamente tratado por Figueiredo et al. (2012), Silva et al. (2015) e Cavalcante et al. $(2012,2015)$. Embora todos os casos analisados remetam às famílias, não se pode deixar apenas na sua responsabilidade a obrigação de cuidar dos avôs, avós, empregadas domésticas idosas e outras pessoas que deram suas vidas para o bem-estar dos adultos de hoje. A forma como a maioria dessas idosas e desses idosos é deixada e esquecida numa ILPI aprofunda neles a ideia de que constituem um peso social, de que são descartáveis e de que não têm mais valor. Para alguns poucos, como se observou nesta pesquisa, apenas a religião tem servido de apoio e de alívio. Mesmo assim, esse fator não tem sido relevante para impedir pensamentos e tentativas suicidas na maioria dos casos analisados.

Em resumo, neste artigo, tentamos entrar nas entranhas das percepçóes, sentimentos, atitudes e práticas de um grupo de idosos com comportamento suicida, que geralmente não é ouvido, por ser muito duro o recado que ele transmite: "perdemos o sentido da vida." Consideramos que o maior mérito deste trabalho é ter trazido à tona as histórias e as razóes da desesperança na voz das pessoas entrevistadas que tentaram ou desejam antecipar seu fim. As limitaçóes do estudo são muitas: o pequeno número de pessoas ouvidas e a impossibilidade, por falta de espaço neste artigo, de apresentar uma contextualização das ILPI e da rotina da vida institucional. Fizemos uma escolha ao dar ênfase a singularidades das narrativas. Por isso, este texto apenas nos permite concluir que prevenir o suicídio é uma ação de apoio e compaixão que exige atenção personalizada das pessoas idosas, por parte das famílias, dos serviços sociais e de saúde, mas também da sociedade. ${ }^{1}$ 


\section{Referências}

AGÊNCIA NACIONAL DE VIGILÂNCIA SANITÁRIA. Resolução da Diretoria Colegiada $n^{\circ} 283$, de 26 de setembro de 2005. Regulamento técnico para o funcionamento das instituições de longa permanência para idosos. Brasília: ANVISA, 2005.

ANÍA, B. J. et al. Intentos de suicidio y suicidios consumados por los ancianos de una residencia. Rev. Esp. Geriatr. Gerontol, v. 38, n. 3, p. 170-174, 2003.

AWATA, S. et al. Validity and utility of the Japanese version of the WHO-Five Well-Being Index in the context of detecting suicidal ideation in elderly community residents. Int Psychogeriatr, v. 19, n. 1, p. 77-88, 2007.

BEAUTRAIS, A. L. Women and suicidal behavior. Crisis, v. 27, n. 4, p. 153-156, 2006.

BOSI, E. Memória e sociedade: lembranças de velhos. São Paulo: Queiroz, 1987.

BERTAUX, D. Biography and Society. The Life History Approach in the Social Sciences. London: Sage Publications, 1981.

BOTEGA, N. J. et al. Prevenção do comportamento suicida. Psico. Porto Alegre, v. 37, n. 3, p. 213-220, 2006.

BRADVICK, L.; BERGLUNG, M. Repetition and severity of suicide attempts across the life clicle: a comparison by age group between suicide victims and controls with severe depression. BMC Psychiatry, v. 9, n. 62, 2009.

CAMARANO, A. A.; KANSO, S. As instituiçôes de longa permanência para idosos no Brasil. Revista Brasileira de Estudos Populacionais, v. 27, n. 1 p. 232-235, 2010.

CANADIAN MENTAL HEALTH ASSOCIATION. The Relationship between suicide and mental health. Disponível em: <http://toronto.cmha.ca/mental_health/the-relationshipbetween-suicide-and-mental-illness/\#.V-VLHIWcE2x>. Acesso em: 26 set. 2016.

CAVAlCANTE, F. G; MINAYO, M. C. S; MANGAS R. M. N. Diferentes faces da depressão no suicídio em idosos. Ciênc. Saúde Coletiva. 2013, 18 (10): 2985-2994.

CAVALCANTE, F. G.; MINAYO, M. C. S. Autópsias psicológicas e psicossociais de idosos que morreram por suicídio no Brasil. Ciênc. Saúde Coletiva, v. 17, n. 8, p. 1943-1954, 2012.

Estudo qualitativo sobre tentativas e ideaçôes suicidas com 60 pessoas idosas brasileiras. Ciênc. Saúde Coletiva, v. 20, n. 6, p. 1655-1666, 2015.

CAVALCANTE, V. C. et al. Religiosidade, ideações e tentativas de suicídio em idosos. In: MINAYO M. C. S.; FIGUEIREDO, A. E. B.; SILVA, R. M. (Org.). Comportamento suicida de pessoas idosas. Editorial UFC, 2016, p. 269-288.

CLEARY, A. Suicidal action, emotional expression and the performance of masculinities. Soc Sci Med, v. 74, n. 4, p. 498-505, 2012. 
DURKHEIM, É. O suicídio: estudo de Sociologia. 2. ed. São Paulo: Editora WMF Martins Fontes, 2011.

FIGUEIREDO, A. E. B. et al. Impacto do suicídio da pessoa idosa em suas famílias. Ciênc. Saúde Coletiva. Rio de Janeiro, v. 17, n. 8, ago. 2012.

FIGUEIREDO, A. E. B. et al. É possível superar ideaçôes e tentativas de suicídio? Um estudo sobre idosos. Ciênc. Saúde Coletiva. Rio de Janeiro, v. 20, n. 6, jun. 2015.

FIGUEIREDO, A. E. B.; MINAYO, M. C. S.; MANGAS, R. M. N. Cuidar de si e cuidar do outro: a percepção dos profissionais e gestores das instituiçôes de longa permanência. In: MINAYO, M. C. S.; FIGUEIREDO, A. E. B.; SILVA, R. M. (Org.). Comportamento suicida de pessoas idosas. Editorial UFC, 2016, p. 415-437.

FLECK, M. P. A. et al. Desenvolvimento do WHOQOL módulo espiritualidade, religiosidade e crenças pessoais. Revista Saúde Pública, v. 37, n. 4, p. 446-455, 2003.

GOY, J. Histoire Orale. Annales de Vaucresson (Encyclopaedia Universalis. Trajectoires de femmes dans la famille ouvrière. Histoires de vies, histoires de familles, trajectoires sociales). Paris, n. 26, supl. p. 743, 1980.

HALBWACHS, M. A memória coletiva. São Paulo: Vértice: Editora Revista dos Tribunais, 1990.

HEISEL, M. J. et al. Concordance of self-and proxy-reported suicide ideation in depressed adults 50 years of age or older. Can J Psychiatry, v. 56, n. 4, p. 219-226, 2011.

KLONSKY, E. D. et al. Hopelessness as a predictor of attempted suicide among first admission patients with psychosis: A 10 year cohort study. Suicide Life Threat Behav, v. 42, n. 1, p. 1-10, 2012.

KU, Y. C. et al. Suicide experiences among institutionalized older veterans in Taiwan. Gerontologist, v. 49, n. 6, p. 746-54, 2009.

LYKOURAS, L. et al. Psychotic (deulional) major depression in elderly and suicidal behaviour. J Affect Disord, v. 19, n. 1-3, p. 225-229, 2002.

MALFENT, D. et al. Suicidal ideation and its correlates among elderly in residential care homes. International Journal of Geriatric Psychiatry, v. 25, n. 8, p. 843-849, 2010.

MANGAS, R. M. et al. Caracterização das instituições de longa permanência no Estado do Rio de Janeiro. In: MINAYO, M. C. S.; FIGUEIREDO, A. E. B.; SILVA, R. M. (Org.). Comportamento suicida de pessoas idosas. Editorial UFC, 2016, p. 343-367.

MAY, A. M.; KLONSKY, E. D.; KLEIN, D. N. Predicting future suicide attempts among depressed suicide ideators: a 10 year longitudinal study. J Psychiatr Res, v. 46, n. 7, p. $946-$ $952,2012$.

MENEGHEL, S. N. et al. Tentativa de suicídio em mulheres idosas - uma perspectiva de gênero. Ciênc. Saúde Coletiva. Rio de Janeiro, v. 20, n. 6, p. 1721-1730, jun. 2015. 
MENEGHEL, S. N. et al. Suicídio de idosos sob a perspectiva de gênero. Ciênc. Saúde Coletiva. Rio de Janeiro, v. 17, n. 8, p. 1983-1992, ago. 2012.

MENTAL HEALTH REPORTING. Facts about mental illness and suicide. Recovering happens. Disponível em: <http://depts.washington.edu/mhreport/facts_suicide.php>. Acesso em: 26 set. 2016.

MINAYO, M. C. S. et al. Trends in suicide mortality among Brazilian adults and elderly 1980-2006. Revista de Saúde Pública (Impresso), v. 46, p. 300-309, 2012

MINAYO, M. C. S.; CAVALCANTE, F. G. Estudo compreensivo sobre suicídio de mulheres idosas de sete cidades brasileiras. Cad. Saúde Pública. Rio de Janeiro, v. 29, n. 12, p. 2405-2415, dez. 2013.

. Suicide attempts among elderly people: literature review (2002/2013). Cienc. Saúde Coletiva. Rio de Janeiro, v. 20, n. 6, p. 1751-1762, 2015.

MINAYO, M. C. S.; FIGUEIREDO, A. E. B.; MANGAS, R. M. N. Relatos de vida de pessoas idosas institucionalizadas com comportamento suicida. In: MINAYO, M. C. S.; FIGUEIREDO, A. E. B.; SILVA, R. M. (Org.). Comportamento suicida de pessoas idosas. Editorial UFC, 2016, p. 385-414.

PINTO, L. W.; ASSIS, S. G.; PIRES, T. O. Mortalidade por suicídio em pessoas com 60 anos ou mais nos municípios brasileiros no período de 1996 a 2007. Ciênc. Saúde Coletiva. Rio de Janeiro, v. 17, n. 8, p. 1963-1972, 2012.

SCOCCO, P. et al. Suicidal behaviour in nursing homes: a survey in a region of north-east Italy. Int J Geriatr Psychiatry, n. 21, p. 307-311, 2006.

SCOCCO, P. et al. Death ideas, suicidal thoughts, and plans among nursing home residents. J Geriatr Psychiatry Neurol, n. 22, p. 141-148, 2009.

SILVA, R. M. et al. Influências dos problemas e conflitos familiares nas ideaçóes e tentativas de suicídio de pessoas idosas. Ciênc. Saúde Coletiva. Rio de Janeiro, v. 20, n. 6, jun. 20, 2015. SILVA, R. M. et al. Problemas na formação que interferem nos cuidados profissionais de idosos com comportamento suicida. In: MINAYO, M. C.; FIGUEIREDO, A. E. B.; SILVA, R. M. (Org.). Comportamento suicida de idosos. Fortaleza: Edições UFC, 2016.

SZANTO, K. et al. Identification of suicidal ideation and prevention of suicidal behaviour in the elderly. Drugs Aging, v. 19, n. 1 p. 11-24, 2002.

TURVEY, C. L. et al. Risk factors for late-life suicide: a prospective, community-based study. Am J Geriatr Psychiatry, v. 10, n. 4, p. 398-406, 2002.

WIKTORSSON, S. et al. Prospective cohort study of suicide attempters aged 70 and above: one-year outcomes. J Affect Disord, v. 134, n. 1-3, p. 333-340, 2011. 
WORLD HEALTH ORGANIZATION. Global report on violence and health. Genève: WHO, 2002.

. Preventing suicide: a global imperative. Genève: WHO, 2014.

YIP, P. S. F. et al. A prevalence study of suicide ideation among older adults in Hong Kong SAR. Int J Geriatr Psychiatry, v. 18, n. 11, p. 1056-1062, 2003.

\section{Nota}

1 M.C.S Minayo, A.E.B. Figueiredo e R.M.N. Mangas participaram integralmente de todas as etapas de elaboração do artigo e da coleta dos dados da pesquisa que o originou. 


\section{The suicidal behavior of institutionalized elderly: life stories}

This article summarizes and analyzes 16 life histories of elderly men and women residing in nine Long Stay Institutions in the State of Rio de Janeiro and who tried to end life or have suicidal behavior. The qualitative study was preceded by a survey of the profile of 122 elderly residents, using a form that includes: socioeconomic and demographic data: name, date of birth, age, sex, marital status, number of children living and dead, nationality, race, religion, degree of education, profession / occupation, income and time in which the institution resides; And five questions that guided the selection of people with ideations and suicide attempts, according to a model created by the Italian researcher Scocco and his group. According to the stories narrated by the eight men and eight women, there are relevant gender differences in both socio-demographic and motivational aspects of suicidal behavior. The main factors common to institutionalized men and women at risk for self-inflicted death are: loss of affective and referential ties, alcohol and other drug abuse, inadequate institutional life, disabling and painful chronic diseases that lead to loneliness, hopelessness and meaninglessness to life.

> Keywords: elderly; suicide; suicide attempt; suicide ideation; institution. 